\title{
REFLECTION
}

\section{METIS: a Swedish programme to boost recruitment in psychiatry}

\author{
Simon Kyaga
}

Simon Kyaga is a senior consultant in psychiatry at Lidingö Mood

Disorders Out-Patient Clinic and Karolinska Institutet in Stockholm,

Sweden. He is a medical advisor to the National Board of Health and Welfare in Sweden and co-opted on the board of the Swedish Psychiatric Association. Correspondence Dr Simon Kyaga Department of Epidemiology and Biostatistics, Karolinska Institutet, Box 281, 17177 Stockholm,

Sweden. Email: simon.kyaga@ki.se

\section{SUMMARY}

Psychiatrists are wanting in Sweden and many other countries. Among Swedish efforts to improve specialist training in psychiatry and to make a future psychiatric career attractive is a national course-based project named METIS. An evaluation of METIS courses run between 2007 and 2012 revealed that, in parallel with the initiative, the number of doctors obtaining proofs of specialist competence in psychiatry increased by more than a third. This article outlines current specialist training in Sweden and describes how the 40 -hour METIS programme fits within it.

\section{DECLARATION OF INTEREST}

S. K. has been involved in the development of a METIS course on mood disorders.

The field of psychiatry is rapidly developing and the need for psychiatric interventions is continually increasing (Institute for Health Metrics and Evaluation 2013). However, there is a shortage of specialist trained psychiatrists in Sweden and many other countries (Goldacre 2013; Kastrup 2013). The Swedish specialist training for physicians involves learning through clinical work, tutoring and participation in courses. Efforts to improve specialist training in psychiatry aim to increase the skills of the physicians who complete it and to make a future psychiatric career more attractive. A recent successful initiative for specialist training in psychiatry has been a national course project named METIS (Metis was the mother of Athena, Greek goddess of wisdom and knowledge). The project was supervised by Raffaella Valigi Björck.

\section{Swedish specialist training in psychiatry}

The current regime for specialist training in psychiatry in Sweden was introduced on 1 July 2006 (Box 1). During at least 5 years of education, trainees are required to meet some 20 learning goals, such as diagnosis and treatment of mood disorders, somatic differential diagnosis, management and scientific knowledge. The method of learning, for example during clinical practice or on courses, and how goal achievement should be assessed are specified under each goal description. In many cases, learning methods include a course that corresponds to the content of the goal. Goal descriptions are general and complemented by more detailed recommendations from the Swedish Psychiatric Association. However, specialist training courses in psychiatry were limited and plans were made to improve the situation.

\section{METIS}

In 2006, the Swedish Psychiatric Association and the Swedish Association of Local Authorities and Regions made a joint application to the Ministry of Health for support of a new project, METIS. Funds were granted in 2007, and overall the project received about $£ 3.58$ million in state funding between 2007 and 2012. The METIS project

\section{BOX 1 Swedish medical training and specialist training in psychiatry}

All Swedish physicians are required to complete $5 \frac{1}{2}$ years at medical school, followed by an 18-month internship. While at medical school, students generally take a course in clinical psychiatry lasting about 5 weeks, including both theoretical studies and clinical rotation, followed by an exam. The internship includes a 3-month clinical rotation in psychiatry. The internship is concluded with an exam, which if successful leads to formal registration by the National Board of Health and Welfare.

Registered physicians may then apply for specialist training, which takes a further 5 years. Specialist training in adult psychiatry or child and adolescent psychiatry mainly consists of clinical rotations in different areas of psychiatry, as well as in neurology and internal medicine, in parallel with an obligatory 2-year course in psychotherapy and other courses in subjects relevant for psychiatry. All activities are documented by the specialist training physician and, on completion, submitted to the National Board of Health and Welfare responsible for the formal assessment of goal attainment and issuing of the proof of specialist competence. There is no system for examination or revalidation of specialist competence in Sweden. 
is just one of several activities that the Swedish government has undertaken with the long-term aim of increasing the number of specialists in psychiatry (Kastrup 2013).

\section{Educational framework}

The METIS project is based on constructive alignment integrating theory and practice (Biggs 2011; Kastrup 2013) and its purpose is to supplement standard specialist training. A METIS course consists of three parts: phase 1 lasts for 6 weeks, phase 2 for 3 days, and phase 3 for 8 weeks, with a final examination. The time commitment for the course is specified at 40 hours. Trainees may choose the courses they attend, but all necessary learning goals need to be covered before they apply to the National Board of Health and Welfare for assessment of formal specialist competence. Many trainees also attend extra courses according to their professional interests.

\section{Phase 1}

The first phase takes place in the trainee's home clinic, where the participant receives access to an online learning platform, with course objectives, literature and preparations to be made for the ensuing course meeting in phase 2 . At the end of phase 1 , the trainee takes a web-based selfcorrecting test with multiple choice questions. To move on to phase 2 at least $80 \%$ of these questions have to be answered correctly.

\section{Phase 2}

The second phase is a course meeting lasting 3 days. Participants are offered lectures and activities such as case discussions, video cases and exercises, to give them a deeper knowledge of what has been learned during the previous phase.

Following the course meeting, the trainee returns to clinical work, and the third phase of the course commences.

\section{Phase 3}

This final phase is concluded with an examination, in which participants are required to write, for example, a case presentation and recommend treatment based on learning in phases 1 and 2. A period of 8 weeks is allowed to identify a suitable case and to write the examination. The reason for placing the examination at the participant's workplace is that it should be clinically relevant, but also to provide an opportunity for experiential learning (Kolb 1984), where the learner has a concrete experience and is given the opportunity (and task) to reflect on it.

\section{What has METIS achieved?}

In all, 22 subject courses have been developed and 92 courses were held for a total of 2309 participants during 2007-2012. A faculty of about 200 teachers has been recruited nationally; the need for courses for specialist training in psychiatry is now almost covered. The number of issued proofs of specialist competence in psychiatry increased over the project period from 119 in 2007 to 163 in 2012 (from about 1.3 per 100000 inhabitants in 2007 to 1.7 per 100000 in 2012) (Kastrup 2013).

\section{The future of Swedish specialist training}

Aside from a small difference in its duration (Fig. 1), the major difference between Swedish and British specialist training is that British training is considerably more structured and formally assessed. In addition, Sweden has no tradition of formalised continuing professional development following attained specialist competence. The latter question was recently addressed by Professor Friberg, chair of the Swedish Society of Medicine. In a statement following a meeting of the representative assembly in October 2013, he argued that:

'Requirements must be imposed and the Swedish Society of Medicine will provide frameworks, comprehensive definition of requirements and legitimacy while it is the responsibility of each specialist section to indicate the specialty-specific requirements' (Swedish Society of Medicine 2013).

Thus, METIS can be seen as an attempt by the Swedish Psychiatric Association to align with a more formal structure for course modules during specialist training inspired by the British tradition. However, some concerns have been made that the funding of METIS, with its comprehensive curriculum and obligatory examination, has made other courses economically inviable and clinical duties difficult to keep up with, while also contributing to an ever-increasing regulation of the medical profession. These concerns echo

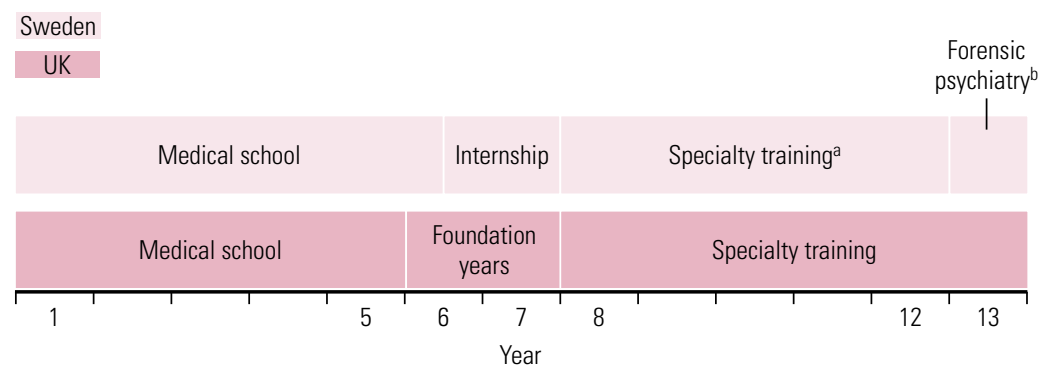

FIG 1

Duration of medical and specialist psychiatric training in Sweden and the UK. a, minimum of 5 years' training in adult psychiatry or child and adolescent psychiatry; $b$, for specialists in adult psychiatry only. 
similar worries raised in the UK (e.g. MatthewsKing 2013).

The increase of issued proofs of specialist competence in psychiatry in Sweden during the METIS project is encouraging. Furthermore, METIS courses were generally well received: the overall evaluation of the 92 METIS courses shows a high average score of 4.74 (on a scale of 1 to 6, 'very bad' to 'very good') (Kastrup 2013). Nevertheless, it is not certain that further regulation of the psychiatric profession will make a future career in psychiatry more attractive.

\section{References}

Biggs JB, Tang C (2011) Teaching for Quality Learning at University: What the Student Does (4th edn). Society for Research into Higher Education/ Open University Press.
Goldacre MJ, Fazel S, Smith F, et al (2013) Choice and rejection of psychiatry as a career: surveys of UK medical graduates from 1974 to 2009. British Journal of Psychiatry, 202: 228-34.

Institute for Health Metrics and Evaluation (2013) The Global Burden of Disease: Generating Evidence, Guiding Policy. IHME, University of Washington.

Kastrup A (2013) METIS-projektet - uppföljning av SK-kurser i psykiatri 2007-2012. Slutrapport [METIS Project - Follow-Up of SK Courses in Psychiatry 2007-2012. Final Report]. Socialstyrelsen.

Kolb D (1984) Experiential Learning: Experience as the Source of Learning and Development. Prentice Hall.

Matthews-King A (2013) Furious GPC negotiator predicts revalidation 'revolt' as GPs spend more than 40 hours preparing for appraisals. Pulse, 27 Nov.

Swedish Society of Medicine (2013) Nytt från fullmäktigemötet [News from the representative assembly] [online]. Swedish Society of Medicine (http://sls.se/Aktuellt/Senaste-nytt/Kerstin-Nilsson-Orebro-och-StefanLindgren-Malmo-ny-ordforande-och-vice-ordforande-i-Lakaresallskapet). Accessed 4 Mar 2014 